\title{
Corneal diameter in premature infants
}

\author{
Khaled U Al-Umran, Maurizio F Pandolfi
}

\begin{abstract}
The size of the cornea is important in the diagnosis of primary infantile glaucoma. Reference values regarding eyes of premature infants are scarce. Such data are of special importance in areas such as the Middle East where infantile glaucoma is common and often evident already at birth. The authors have measured the horizontal corneal diameter of the eyes of 127 premature Saudi infants with a gestational age between 23 and 36 weeks and a birth weight ranging from $540 \mathrm{~g}$ to $4720 \mathrm{~g}$. The corneal diameter ranged from $7.75 \mathrm{~mm}$ to $10 \mathrm{~mm}$. The smallest diameter $(7.75 \mathrm{~mm})$ was found in an infant with a gestational age of 23 weeks and having a birth weight of $520 \mathrm{~g}$. The largest diameter $(10 \mathrm{~mm})$ belonged to two infants with a gestational age of 34 and 35 weeks and a birth weight of $2250 \mathrm{~g}$ and $2240 \mathrm{~g}$ respectively. Corneal diameter was positively correlated $(p<0.001)$ with gestational age and birth weight. Graphs depicting the regression line of corneal diameter on gestational age and of corneal diameter on birth weight together with the $95 \%$ confidence limits for individual values are provided for reference.
\end{abstract}

King Fahd Hospital of the University, Al-Khobar, Saudi Arabia, Department of Pediatrics K U Al-Umran

Department of
Ophthalmology
M F Pandolfi
Correspondence to:
Dr Khaled Al-Umran,
Department of Pediatrics,
King Fahd Hospital of the
University, PO Box $40140, \mathrm{Al}-$
Khobar 31952 , Saudi Arabia.
Accepted for publication
3 October 1991

Figure 1 Modified caliper and retractor used for corneal measurement. In order to minimise the risk of injuring the eye the steel points of the caliper have been replaced with thin, flexible copper

wires.
An enlarged, often cloudy, cornea is the most evident sign of primary infantile glaucoma. The presence of these signs already at birth has a bad prognostic significance since it implies an intrauterine onset of the disease resulting in a defective development of the eyeball. ${ }^{2}$ However a cloudy cornea although of normal size is present in a number of other diseases such as sclerocornea, Peter's anomaly, and congenital hereditary endothelial dystrophy. ${ }^{3}$

Sometimes premature neonates are born with a cloudy cornea and knowing whether this cornea is pathologically enlarged or not may be relevant for the diagnosis. However our knowledge of the corneal diameter of healthy premature eyes is limited to a few cadaver eyes and 37 premature infants. $^{5}$

This paper deals with the measurement of the

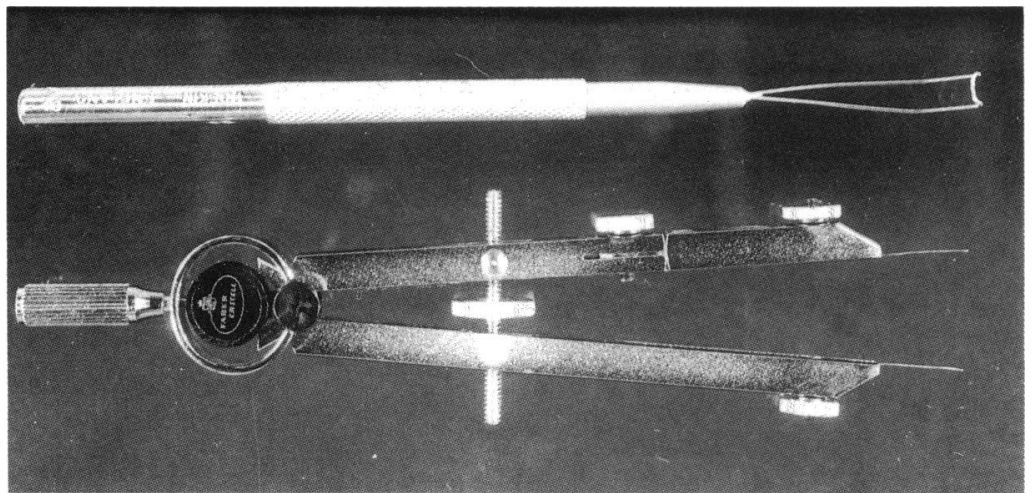

corneal diameter in 127 premature Saudi infants with healthy eyes.

\section{Material and methods}

The corneal diameter was measured in 127 premature infants with gestational ages ranging from 23 to 36 weeks the mean age being $33 \cdot 1$ (SD 2.98 ) weeks. The weight at birth ranged from 540 to $4720 \mathrm{~g}$, the mean weight being 1950 (SD $614) \mathrm{g}$. The corneal diameter was measured in both eyes but one randomly selected diameter right or left - from each neonate was used for statistical calculations. Neonates showing ocular pathology, somatic anomalies, or having uncertain gestational age were excluded. The measurement (horizontal diameter, white to white) took place during the first week of life but in six cases was made immediately after death. It was performed with the help of a caliper modified to prevent corneal injury (Fig 1). In order to obtain a good visualisation of the eye the upper lid was cautiously lifted using a wire loop retractor (Fig 1). Often the lid retractor was not applied, gentle manipulation being sufficient to obtain a satisfactory separation of the lids. The caliper reading was translated into $\mathrm{mm}$ using a set of finely graduated precision rulers. The meaurements were approximated to $0.25 \mathrm{~mm}$. Virtually all measurements were made by one investigator $(\mathrm{KU})$.

\section{Results}

The corneal diameter ranged from $7 \cdot 75 \mathrm{~mm}$ to 10 $\mathrm{mm}$. In the eyes of 16 infants measurements varied by $0.25 \mathrm{~mm}$, in two by $0.5 \mathrm{~mm}$, and were identical in the rest. The smallest diameter $(7.75 \mathrm{~mm})$ was found in an infant with a gestational age of 23 weeks and having a birth weight of $520 \mathrm{~g}$. The largest diameter $(10 \mathrm{~mm})$ belonged to two infants with a gestational age of 34 and 35 weeks and a birth weight of $2250 \mathrm{~g}$ and $2240 \mathrm{~g}$ respectively.

The corneal diameter correlated positively with the gestational age (Fig 2) and with birth weight (Fig 3). In both cases the correlation coefficient was significant at $99 \%$ level being 0.827 for the diameter and the age, and 0.746 for the diameter and the weight. The $95 \%$ confidence interval for the mean and the $95 \%$ confidence interval for individual values are also shown in Figures 2 and 3.

\section{Discussion}

The mean horizontal diameter of human cornea at birth is reported to be $10.0 \mathrm{~mm} .{ }^{6}$ With regard to the corneal diameter of premature infants no data are available in the literature. According to this study in 127 premature babies with gestational ages between 23 and 36 weeks the corneal 


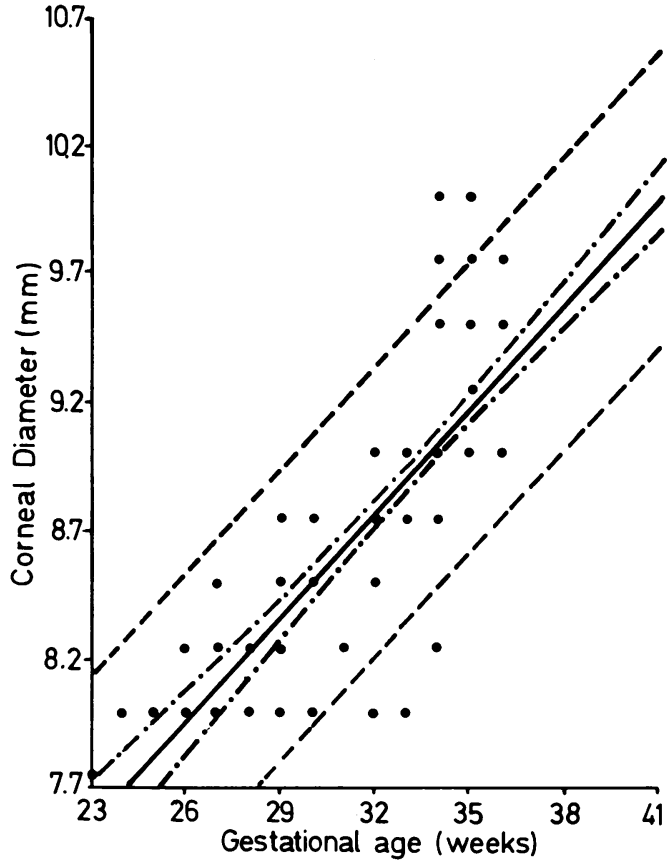

Figure 2 Regression of corneal diameter $(\mathrm{mm})$ on gestational age (weeks). The solid line is the best fit regression line. Inner dotted lines represent the $95 \%$ confidence limits for the predicted mean corneal diameter. Outer dotted lines represent the $95 \%$ limits for individual diameter values.

diameter ranged from a minimum of $7.75 \mathrm{~mm}$ to a maximum of $10 \mathrm{~mm}$. There was a clear positive correlation between corneal diameter and gestational age or birth weight.

The walls of neonatal eyes, and even more so those of fetal eyes, are distended by an increased intraocular pressure because the corneal and scleral collagen has not yet sufficiently hardened. ${ }^{7}$ Before the age of 6 months the rigidity of the cornea is less than that of the sclera; consequently the cornea enlarges more rapidly under the influence of an increased IOP. ${ }^{8}$ Secretion of aqueous humour presumably begins before birth as suggested by the findings of some degree of aqueous drainage effective by $17-18$ weeks of fetal life. ${ }^{9}$ Fetal facility of outflow correlates directly with the diameter of the cornea. ${ }^{9}$ The existence of a fetal aqueous humour circulation has recently been corroborated by a scanning electron microscopy study showing by 18-22 weeks of development the presence of a well formed gap system connecting the anterior chamber with the developing intertrabecular spaces. ${ }^{10}$ These data underline the importance of the corneal size in the diagnosis of developmental glaucoma in premature neonates and make it necessary to have reference values available.

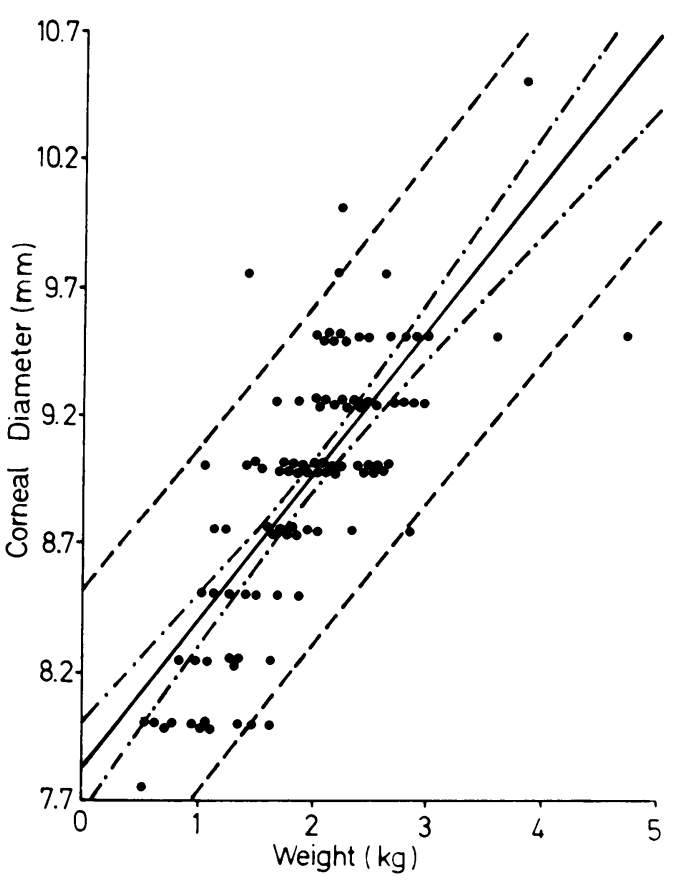

Figure 3 Regression of corneal diameter $(\mathrm{mm})$ on birth weight (kg). The solid line is the best fit regression line. Inner dotted lines represent the $95 \%$ confidence limits for the predicted mean corneal diameter. Outer dotted lines represent the $95 \%$ limits for individual diameter values.

Knowing the normal corneal diameter in these children at different gestational age and birth weight is of special interest in areas such as the Middle East where the disease is common and often evident already at birth. ${ }^{.1}$

1 Worst JGF. The cause and treatment of congenital glaucoma. Trans Am Acad Ophthalmol Otol 1964; 766-88.

2 Morin JD. Primary infantile glaucoma: influence of age at

onset. Can 7 Ophthalmol 1983; 18: 233-4. management. Philadelphia: Saunders, 1984: 29.

management. Philadelphia: Saunders, $1984: 29$.
4 Sorsby A, Sheridan $M$. The eye at birth: measurement of the principal diameters in forty eight cadavers. $\mathcal{F}$ Anat $1960 ; 94$ : princip.

5 Musarella MA, Morin JD. Anterior segment and intraocular pressure measurement of the unanesthetized premature
infant. Metab Pediatr Syst Ophthalmol 1985; 8: 53-60.

$6 \mathrm{Kwitko}$ ML. Surgery of the infant eye. New York: AppletonCentury-Crofts, 1979: 11.

7 De Luise VP, Anderson DR. Primary infantile glaucoma (congenital glaucoma). Surv Ophthalmol 1983; 28: 1-19.

$8 \mathrm{Kwitko}$ ML. The pathogenesis of symptoms in congenital glaucoma. XXI Concillum Ophthalmologicum Parisi 1970, Acta pars II, Solares MP, ed. Amsterdam: Excerpta Medica, Acta par.

9 Pandolfi M, Åstedt B. Outflow resistance in the fetal eye. Acta Ophthalmol 1971; 49: 344-50.

10 McMenamin PG. Human fetal iridocorneal angle: a light scanning electron microscopic study. Br f Ophthalmol 1989; 73: 871-6.

11 Kazi GA, Jaafar MS, Traverso CE, Tomey KF. One year experience of congenital glaucoma at KKESH, Riyadh, Saudi Arabia. Proceedings of the 3rd Annual Symposium on New Development in Ophthalmology at KKESH. Riyadh, 1986: 253-4. 